\title{
Capsule Commentary on Kurani et al., Use of Potentially Nephrotoxic Medications by U.S. Adults with Chronic Kidney Disease: NHANES, 201 1-2016
}

\author{
Julie Machen, MD

Dell Medical School at the University of Texas at Austin, Austin, TX, USA.

stage 3 disease. However, based on this study, increasing patient awareness of CKD is not sufficient for optimal CKD management. Clinicians also need to regularly review medications with CKD patients.

Corresponding Author: Julie Machen, MD; Dell Medical School at the University of Texas at Austin, Austin, TX, USA (e-mail: Julie. machen@austin.utexas.edu).

use of potentially inappropriate medications (PIM) in patients with chronic kidney disease (CKD), using a crosssectional analysis of 2011-2016 NHANES data. The authors also explored the relationship between CKD stage, patient awareness of CKD, and PIM use. Results showed that PIM use is common in patients with CKD, with $>50 \%$ of patients across all CKD stages using PIM. Patient unawareness of their kidney disease was high, especially in patients with stage 3 CKD $(91.6 \%$ in stage $3 \mathrm{a}, 73.1 \%$ in stage $3 \mathrm{~b})$. There was no association between patient awareness of CKD and odds of PIM use.

This is an important area of investigation because people with CKD are at risk for adverse events and disease progression with nephrotoxic medications. ${ }^{2}$ Prescribing medications to people with CKD is often complicated, because these patients commonly have multiple comorbidities and require many medications. ${ }^{3}$ A limitation of this study is that it does not address this complex decision-making. The cross-sectional analysis only showed if medicines were prescribed, so it did not reveal details about the prescribers' decision-making process or discussions with patients about the risks and benefits of taking PIM.

Despite this limitation, the study adds to existing literature suggesting that we overuse PIM in patients with CKD. ${ }^{4,5}$ Based on the study data, providers need to do a better job at communicating CKD diagnoses, especially in patients with

\section{Compliance with Ethical Standards:}

Conflict of Interest: The author has no conflicts of interest with this article.

\section{REFERENCES}

1. Kurani SS, Jeffery MM, Thorsteinsdottir B, Hickson LJ, Barreto EF, Haag JD, Giblon R, Shah ND, McCoy RG. Use of Potentially Nephrotoxic Medications by U.S. Adults with Chronic Kidney Disease: NHANES, 20112016. J Gen Intern Med. DOI: https://doi.org/10.1007/s11606-01905557-8

2. KDIGO. KDIGO 2012 Clinical practice guideline for the evaluation and management of chronic kidney disease. Kidney Int Suppl 2013;3(1):1-150.

3. Stevens LA, Li S, Wang C, Huang C, Becker BN, Bomback AS, et al. Prevalence of CKD and comorbid illness in elderly patients in the United States: results from the Kidney Early Evaluation Program (KEEP). Am J Kidney Dis 2010;55(3 Suppl 2):S23-33.

4. Tseng CL, Soroka O, Maney M, Aron DC, Pogach LM. Assessing potential glycemic overtreatment in persons at hypoglycemic risk. JAMA Intern Med 2014; 174(2):259-68.

5. Zhan M, St. Peter WL, Doerfler RM, Woods CM, Blumenthal JB, Diamantidis CJ, et al. Patterns of NSAIDs use and their association with other analgesic use in CKD. Clin J Am Soc Nephrol 2017;12(11):1778-86.

Publisher's Note Springer Nature remains neutral with regard to jurisdictional claims in published maps and institutional affiliations. 